Disponível em:

http://editora.unoesc.edu.br/index.php/race

RACE, Joaçaba, v. 17, n. 2, p. 757-782, maio/ago. 2018

\title{
RELAÇÃO ENTRE O VALOR ADICIONADO DAS ATIVIDADES ECONÔMICAS E O PRODUTO INTERNO BRUTO DO RIO GRANDE DO NORTE
}

Relationship between the added value of the economic activities and the Gross Domestic

Product of Rio Grande do Norte

Ruhama Bezerra Fernandes

E-mail: ruhama.bezerra@gmail.com

Graduada em Ciências Contábeis pela Universidade Federal do Rio Grande do Norte; Mestranda na Universidade Federal do Rio Grande do Norte; Bolsista Capes na Universidade Federal do Rio Grande do Norte. Endereço para contato: Avenida Senador Salgado Filho, 3000, Lagoa Nova, 59078970, Natal, Rio Grande do Norte, Brasil.

Adilson de Lima Tavares

E-mail: adilson.tavares@uol.com.br

Doutor e Mestre em Ciências Contábeis pelo Programa Multi-institucional e Inter-regional de Pós-graduação em Ciências Contábeis UnB/UFPB/UFRN; Professor no Programa de Pós-graduação em Ciências Contábeis da Universidade Federal do Rio Grande do Norte.

Yuri Gomes Paiva Azevedo

E-mail: yuri_azevedo@live.com

Mestre em Ciências Contábeis pela Universidade Federal do Rio Grande do Norte; Bacharel em Ciências Contábeis pela Universidade Federal do Rio Grande do Norte; Professor Substituto no Departamento de Ciências Contábeis da Universidade Federal do Rio Grande do Norte.

Artigo recebido em 12 de maio de 2018. Aceito em 05 de julho de 2018. 


\section{Resumo}

Neste estudo teve-se por objetivo analisar a relação do valor adicionado das principais atividades econômicas (agropecuária, indústria, serviços e administração pública) relativamente ao Produto Interno Bruto (PIB) do Rio Grande do Norte, durante o período de 2010 a 2013. Nesse sentido, foram coletados dados relativos ao valor adicionado, ao PIB e à população no sítio do Instituto Brasileiro de Geografia e Estatística (IBGE), bem como referentes ao Índice Firjan de Desenvolvimento Municipal (IFDM), por meio do sítio do Sistema Firjan. A amostra compreendeu 166 municípios, de uma totalidade de 167. Para a realização das análises, além da estatística descritiva, foi estimado um modelo de regressão por mínimos quadrados ordinários com dados dispostos em painel, tendo o PIB como variável dependente e as demais variáveis como independentes. Com base nos resultados encontrados, verifica-se que os valores adicionados pelas atividades econômicas apresentam relação positiva e estatisticamente significante, enquanto que as variáveis população e IFDM se relacionam de forma negativa, trazendo à tona questionamentos sobre a distribuição de renda, as políticas socioeconômicas relativas à transição demográfica e a diferença dos conceitos de crescimento e desenvolvimento econômico, corroborando para a hipótese de que o PIB não mede qualidade de vida. Por fim, a partir dos resultados mensurados, conclui-se que os valores adicionados pelas atividades econômicas do Estado do Rio Grande do Norte possuem relação estatisticamente significante com o PIB no período investigado.

Palavras-chave: Produto Interno Bruto. Demonstração do Valor Adicionado. Rio Grande do Norte.

\section{Abstract}

The study aims to analyze the relation of the value added of the main economic activities (agriculture, industry, services and public administration) regarding the Gross Domestic Product of Rio Grande do Norte during the period from 2010 to 2013. In this sense, data on value added, GDP and population were collected on the website of the Brazilian Institute of Geography and Statistics (IBGE), as well as on the Firjan Municipal Development Index (IFDM), through the Firjan System website. The sample comprised 166 municipalities, out of a total of 167. In addition to the descriptive statistics, a regression model was estimated by ordinary least squares with data arranged in a panel, with GDP as a dependent variable and the other variables as independently. Based on the results found, it can be seen that the values added by economic activities have a positive and statistically significant relationship, while the variables population and IFDM were related in a negative way, raising questions about income distribution, socioeconomic policies related to the demographic transition and the difference of the concepts of growth and economic development, corroborating the hypothesis that GDP does not measure quality of life. Finally, from the results measured, it can be concluded that the added values by the economic activities of the State of Rio Grande do Norte have a statistically significant relation with the GDP in the period investigated.

Keywords: Gross Domestic Product. Added Value Statements. Rio Grande do Norte. 


\section{INTRODUÇÃO}

A necessidade de as organizações serem mais transparentes aos diversos usuários das suas informações tem exigido maior divulgação dos relatórios, bem como a expansão do conteúdo informacional (TAIAROL; RAIMUNDINI; BEHR, 2015). Diante dessas novas demandas do mercado globalizado, verifica-se a importância de as organizações procurarem novas alternativas para evidenciar suas políticas sociais e ambientais visando promover a responsabilidade social e reduzir a assimetria informacional (MARTINS et al., 2016).

Nesse contexto surge a contabilidade social juntamente com a macroeconomia "que possibilitaram a evolução da mensuração da economia e a criação de alguns indicadores facilitadores.” (SIQUEIRA, 2014, p. 15). Por meio da contabilidade social é possível analisar não apenas as influências das variações patrimoniais nas entidades, mas também na sociedade e no meio ambiente, satisfazendo o maior número de usuários da informação (KROETZ, 2000).

É nessa temática da contabilidade social que surge o Balanço Social. Segundo Nunes, Ferreira e Araújo (2016) existem quatro vertentes do Balanço Social: Balanço Ambiental, Balanço de Recursos Humanos, Demonstração do Valor Adicionado e benefícios e contribuições à sociedade em geral.

O foco deste estudo está na vertente mensurada pela contabilidade e divulgada por meio da Demonstração do Valor Adicionado (DVA), relatório de natureza econômica, que visa demonstrar o valor gerado pela organização e sua contribuição para os elementos que colaboraram para a sua geração (DE LUCA, 2009).

No Brasil esse demonstrativo passou a ser obrigatório para as empresas de capital aberto a partir da Lei n. 11.638/07. Machado, Macedo e Machado (2015) destacam que apesar de a DVA não ser contemplada nas normas internacionais de contabilidade, emitidas pelo International Accounting Standards Board (IASB), o Global Reporting Initiative (GRI), órgão que promove o uso de relatórios de sustentabilidade, considera o Valor Econômico Gerado e Distribuído como um indicador de desempenho, sendo esse parâmetro semelhante ao valor adicionado.

Nesse sentido, verifica-se a relevância dessas informações em nível internacional, além do aspecto da responsabilidade social presente na DVA, que é considerado sinalização positiva na condução da administração das companhias, conforme evidenciado por Barros et al. (2013), que investigaram a relevância do valor adicionado para os investidores. 
O cálculo da DVA assemelha-se muito ao do indicador socioeconômico do Produto Interno Bruto (PIB). Segundo De Luca (2009), o somatório dos valores adicionados das unidades produtivas dos vários níveis de atividades econômicas seria uma forma de se mensurar o PIB. Em linhas gerais, a DVA apresenta-se como aspecto de verificação do crescimento econômico da empresa e o PIB a mensuração do crescimento econômico do País.

O PIB é o principal indicador utilizado para medir o crescimento econômico de uma região, seja ela uma cidade, estado, país seja mesmo um grupo de nações. A Organização das Nações Unidas (ONU), inclusive, vem conduzindo esforços para padronizar esse indicador para vários países (SIQUEIRA, 2014). As críticas em relação ao PIB referem-se, principalmente, ao fato de ele não medir a qualidade de vida das pessoas, a distribuição de renda, ou seja, o desenvolvimento, mas apenas o crescimento econômico.

De acordo com o levantamento realizado, à época, por Degenhart, Vogt e Hein (2014), existe uma lacuna de pesquisa nos estudos relacionando o PIB com a DVA. Desde então, analisando temporalmente, verifica-se que as pesquisas na área ainda são incipientes.

Assim, partindo da premissa de que cada organização tem parcela contributiva para o PIB e que a DVA demonstra a riqueza gerada por essas organizações, destaca-se a seguinte problemática para nortear a pesquisa: qual a relação do Produto Interno Bruto com o valor adicionado das atividades econômicas dos municípios do Rio Grande do Norte no período de 2010 a 2013?

Nesse sentido, no presente estudo teve-se por objetivo analisar a relação do valor adicionado das principais atividades econômicas (agropecuária, indústria, serviços e administração pública) relativamente ao Produto Interno Bruto (PIB) do Rio Grande do Norte, durante o período de 2010 a 2013.

A relevância deste estudo ampara-se em Silva et al. (2016), haja vista a presença da interdisciplinaridade para a análise das informações que impactam o cenário macroeconômico: relacionando a DVA, variável que se refere às ciências contábeis, com o PIB, outra variável mensurada pelas ciências econômicas. Além disso, segundo levantamento, não foram constatados estudos considerando esse tipo de abordagem que inclua as variáveis de controle (população e IFDM) para serem relacionadas com o PIB.

O presente trabalho está estruturado em cinco seções. Na próxima seção encontra-se o referencial teórico que aborda aspectos das variáveis incluídas no estudo: Demonstração do Valor Adicionado, Produto Interno Bruno, aspecto populacional e 
Índice Firjan de Desenvolvimento Municipal. Na terceira seção apresentam-se os aspectos metodológicos discorrendo sobre os procedimentos utilizados para a análise de dados. A quarta seção contém a análise dos resultados obtidos. Em seguida, na quinta parte, apresenta-se a conclusão, incluindo-se a sugestão para estudos futuros.

\section{REFERENCIAL TEÓRICO}

\subsection{DEMONSTRAÇÃO DO VALOR ADICIONADO}

A Demonstração do Valor Adicionado é parte integrante do Balanço Social e tem por finalidade evidenciar a riqueza criada pela entidade e sua distribuição, durante determinado período (COMITÊ DE PRONUNCIAMENTOS CONTÁBEIS, 2008). Segundo Santos (2007, p. 37) a DVA “deve ser entendida como a forma mais competente criada pela Contabilidade para auxiliar na medição e demonstração da capacidade de geração, bem como de distribuição da riqueza de uma entidade.”

Fonseca e Paiva (2013) afirmam que, ao final dos anos 60 e início dos anos 70 do século $\mathrm{XX}$, a sociedade passou a exigir mais equilíbrio entre o sucesso das empresas e a responsabilidade social delas. Foram iniciados movimentos na França, Alemanha, Inglaterra e Estados Unidos, que corroboraram para o surgimento de um demonstrativo que atendesse aos anseios dos novos usuários da contabilidade.

Dessa forma, surge o Balanço Social, com o objetivo de demonstrar os resultados desembolsados por uma empresa relacionados aos funcionários, comunidades, dependentes, colaboradores e meio ambiente, tendo como primazia a transparência e a ética, e por isso avalia e multiplica o exercício da responsabilidade social (OLIVEIRA et al., 2016).

Nesse contexto, Félix Júnior et al. (2018) evidenciam que à medida que as empresas expõem o Balanço Social, essa demonstração auxilia na legitimação da companhia, mostrando os diversos aspectos sociais, inclusive a preocupação com o corpo funcional das empresas.

Para Machado (2010), entre as vertentes do Balanço Social: Balanço Ambiental, Balanço de Recursos Humanos, Demonstração do Valor Adicionado e benefícios e contribuições à sociedade em geral, a DVA possui mais notoriedade, especialmente pela existência de um modelo padrão, que permite a comparabilidade, a obrigatoriedade de sua publicação para as companhias abertas e a utilização de dados oriundos da contabilidade para a sua elaboração, o que permite maior credibilidade, principalmente quando as demonstrações contábeis são auditadas. 
Por tais motivos é, muitas vezes, tratada separadamente do Balanço Social, de modo semelhante às demais demonstrações contábeis, como, por exemplo, Demonstração do Resultado do Exercício (DRE), Balanço Patrimonial (BP) e Demonstração dos Fluxos de Caixa (DFC).

Entende-se que, em razão da sua relevância, a DVA pode ser tratada como a vertente econômica do balanço social e como a vertente social das demonstrações contábeis. Nesse sentido, Dallabona, Mascarello e Kroetz (2014) destacam que a DVA possui algumas peculiaridades se comparada com outras demonstrações, tendo em vista que seus objetivos podem ser contábeis e sociais.

A DVA contempla mais grupos de interesse na utilização da informação, sobressaindo-se o governo, financiadores, trabalhadores e clientes, o que demonstra de forma mais abrangente a real capacidade da empresa de produzir, agregando ou adicionando valor a seu patrimônio e como essa produção contribui para os diversos fatores da produção.

Assim, Martins et al. (2016) afirmam que a evidenciação de informações por meio da DVA é uma maneira de minimizar os conflitos de interesse gerados pela assimetria informacional, como forma de prestação de contas perante a sociedade.

Analisando historicamente, o cerne das discussões sobre a DVA aponta para a Europa na década de 1970. Segundo Cunha (2002, p. 46), “seu desenvolvimento foi impulsionado pela urgência na introdução do imposto sobre valor agregado nos países europeus.” A literatura destaca, ainda, a influência da Inglaterra, e principalmente, da França e da Alemanha, no sentido de evidenciar a importância desse demonstrativo como ferramenta de divulgação das informações tidas como relevantes para a sociedade.

Em nível internacional, segundo Van Staden (2000), pesquisas empíricas sobre a DVA são escassas provavelmente pelo fato de essa divulgação ser voluntária, já que os padrões internacionais de contabilidade não contemplam a DVA como parte do conjunto de demonstrações financeiras a ser apresentado no relatório anual.

No Brasil, no início do século XXI, de acordo com Cunha, Ribeiro e Santos (2005, p. 11), “cresceram as discussões sobre responsabilidade social das empresas e sua prestação de contas para a sociedade, as empresas brasileiras passaram a sentir a importância do cálculo e da divulgação do valor agregado e sua distribuição”, visualizando como pontos positivos a divulgação da responsabilidade social empresarial, o marketing, bem como o atendimento das cobranças por parte da sociedade.

Nesse contexto, na realidade brasileira as empresas direcionaram objetivos estrategicamente voltados ao bem-estar social e à administração socioeconômica, tornando-se um diferencial competitivo, tendo em vista as desigualdades existentes 
no País e a deficiência do Estado em suprir as demandas sociais (DE SOUSA et al., 2015).

Dessa maneira, ao passo que a competividade cresce cada vez mais, as empresas necessitam modificar antigos padrões, acompanhando o desenvolvimento da sociedade. Tem-se como fator relevante o perfil do consumidor mais consciente e exigente que tem determinado esse repensar das políticas empresariais. É para tanto que a BM\&FBovespa criou o Índice de Sustentabilidade Empresarial (ISE), agrupando em uma carteira de investimentos os retornos das empresas que mais se destacam na área social e ambiental, tornando-se aspecto importante para a imagem da empresa e para atrair investimentos (DE SOUSA et al., 2015).

Quanto à pesquisa, segundo Silva et al. (2016), o Professor Eliseu Martins, da Faculdade de Economia, Administração e Contabilidade da Universidade de São Paulo (FEA-USP) pesquisou, de forma pioneira, a DVA, desde 1980. Posteriormente, destacam-se as duas principais obras sobre o tema, também abordadas pelos professores da mesma Instituição. A primeira, que tem por título Demonstração do Valor Adicionado: do cálculo da Riqueza Criada pela Empresa ao Valor do PIB (DE LUCA, 2009), trata da temática apresentada neste trabalho. Além de disseminar conceitos sobre a DVA, a autora faz a comparação da DVA com o PIB, indicador macroeconômico. A segunda obra, Demonstração do Valor Adicionado (SANTOS, 2007), apresenta aspectos da DVA, assim como o desenvolvimento e a melhoria das condições sociais das empresas e os trabalhos desenvolvidos na área do Balanço Social.

Dessa forma, a DVA que já existia, tendo como base a exigência da Lei n. 11.638/07, tornou-se obrigatória pelo Comitê de Pronunciamentos Contábeis (CPC) à sua elaboração e divulgação para as companhias que têm seu capital negociado em Bolsa de Valores, as chamadas Sociedades Anônimas de Capital Aberto. No termo de aprovação do CPC 09, destaca-se que a DVA, apesar de não ser exigida pelo International Accounting Standards Board (IASB), é incentivada por ele e, também, pela Organização das Nações Unidas (ONU).

Considerado como um instrumento prático, eficaz e útil para complementar os relatórios corporativos em diversos países, Haller e Van Staden (2014) evidenciam que a DVA representa a contribuição monetária de uma entidade para a geração de riqueza de vários grupos da sociedade. Nesse sentido, Costa, Guimarães e Mello (2013) destacam que o compromisso social assumido pelas empresas quando da sua divulgação legitima a imagem de agentes de promoção social bem como favorece o estabelecimento de relação com maior credibilidade entre a empresa e a sociedade, 
fornecendo indícios de que as empresas estão investindo mais na responsabilidade social empresarial.

Para se ter uma ideia da relevância da DVA, muitas regiões, inclusive na África e na Índia, exigem a apresentação desse relatório, ou similar, de qualquer empresa que queira se instalar em seu território, para avaliar quanta riqueza ela é capaz de criar para a localidade, tendo em vista que a sociedade é a detentora dos recursos naturais e humanos utilizados, e muitas vezes, com a exploração desses recursos, não há a constituição de ônus para a empresa (CUNHA, 2002).

Tendo como base a finalidade da DVA, pode-se afirmar que é a demonstração que mais se relaciona com os Pilares da Governança Corporativa (transparência, equidade, prestação de contas e responsabilidade corporativa). Conforme Santos (2007, p. 38), “parece que é inquestionável seu auxílio no cálculo do PIB e de indicadores sociais extremamente importantes. As decisões de investimentos por áreas, regiões, Estados etc. terão nessa demonstração excelente instrumental para a solução de conflitos.” Conforme o Comitê de Pronunciamentos Contábeis (2008), a DVA fundamenta-se em conceitos macroeconômicos e visa apresentar a parcela de contribuição que a entidade apresenta, perante a formação do PIB.

Existem diferenças entre os modelos contábil e econômico no cálculo do valor adicionado: para o modelo econômico, o PIB toma por base a produção; já a contabilidade emprega o conceito contábil da realização das receitas, as vendas, ou seja, baseia-se no regime contábil de competência. Nesse sentido, como a produção e as vendas acontecem normalmente em períodos diferentes, consequentemente o modelo contábil e econômico poderá ser diferente em cada período. Para que os conceitos se igualem, as diferenças entre os estoques inicial e final não devem existir, de forma que tudo que é produzido é vendido no período (COMITÊ DE PRONUNCIAMENTOS CONTÁBEIS, 2008).

\subsection{PRODUTO INTERNO BRUTO}

O Produto Interno Bruto (PIB) é o principal indicador utilizado para medir o crescimento econômico de uma região, seja ela cidade, estado, país seja mesmo um grupo de nações. Segundo Paredes e Oliveira (2017, p. 49), o PIB é “a soma de tudo que é produzido em um espaço geográfico em um dado intervalo de tempo, revelando momentos de expansão e retração.”

O indicador foi criado pelo russo naturalizado americano, o economista Simon Kuznets, na década de 1930. Siqueira (2014) menciona que os estudos estavam 
crescendo acerca da contabilidade social e da macroeconomia na busca pela mensuração dos valores econômicos e sociais dos países, assim como por uma forma de compará-los, surgindo, então, o PIB. Após a Segunda Guerra Mundial, tendo em vista os fins bélicos, o interesse pelo indicador foi intensificado, já que o mundo tinha passado por duas grandes guerras e os países estavam preocupados com a mensuração do seu potencial e de suas estruturas.

Por consequência, na década de 1940, o cálculo moderno de apuração do PIB foi desenvolvido pelo economista britânico Richard Stone, trazendo grande notoriedade internacional para ele, já que o método foi adotado em quase todo o mundo. A ONU, inclusive, segundo Siqueira (2014), tem conduzido esforços de padronizar o sistema de contas nacionais dos vários países, tendo como base esse método. Conforme Silva et al. (2016), Stone também atuou como contador, manifestando, assim, a proximidade das áreas das Ciências Sociais em estudo.

No Brasil, o PIB passou a ser mensurado em 1948. A Fundação Getúlio Vargas era a Instituição à frente do cálculo até 1990, quando o IBGE passou a assumir a responsabilidade. O IBGE tem sido o único órgão responsável pelas medições do crescimento econômico nas esferas municipal, estadual e federal. As medições são realizadas a partir da soma do valor de todos os serviços e bens produzidos na região escolhida, em determinado período (SILVA et al., 2016).

Pode-se concluir que o PIB é a soma do que cada entidade agrega de valor ao processo de produção do seu produto final subtraído das compras dos insumos adquiridos de terceiros. (FEIJÓ; RAMOS, 2013). E, por isso, o crescimento do PIB significa também o aumento do valor adicionado dos bens e serviços, isto é, as empresas estão lucrando mais, e, por isso, produzindo mais. De acordo com Araújo, Fajardo e Tavani (2006, p. 466) o PIB “É o resultado de todos os fatores e atividades da economia, incluindo capital humano, mercado financeiro, imóveis e qualquer outro mercado significativo.”

Observa-se que a literatura menciona como crítica a esse indicador a questão de este medir apenas o crescimento econômico e não o desenvolvimento econômico. Kuznets (1934, p. 7) que criou o PIB afirmou para o Congresso dos Estados Unidos: “o bem-estar de uma nação dificilmente pode ser aferido pela medida da renda nacional.”

Conforme Siqueira (2014), o crescimento econômico conduz à melhoria de certas dimensões da vida cotidiana da empresa, contudo, o conceito de "desenvolvimento” é mais amplo, pois leva em consideração a elevação da qualidade de vida da sociedade e a redução das diferenças econômicas e sociais entre seus membros. 
Philipsen (2015) aprofunda mais sobre o tema. De acordo com o autor, o número do PIB favorece a quantidade de transações de maneira indiscriminada, ou seja, o que conta é o valor agregado que resulta de atividade produtiva, não importando a natureza da transação. Por exemplo, acontecimentos como liquidação dos ativos, batidas de carro, vazamento de óleo, catástrofes naturais que movimentam a economia, mas são essencialmente negativos, adentram no cálculo do PIB.

\subsection{ASPECTO POPULACIONAL}

De acordo com Kurtenbach (2013), nas últimas décadas o Brasil tem passado por transformações demográficas. Em 1970, a estrutura etária do País era jovem. Desde então, a distribuição etária está mudando gradualmente para uma população cada vez mais velha. Essa transformação da sociedade, a transição demográfica, pode refletir em impactos importantes na economia e no crescimento econômico do País.

Alves, Vasconcelos e Carvalho (2010) afirmam que nos clássicos da economia sempre esteve presente a relação entre população e desenvolvimento e destacam que o atual quadro demográfico do Brasil favorece o crescimento econômico. Conforme Alves e Bruno (2006), o primeiro impacto decorrente da transição demográfica é a elevação da parcela da população em idade ativa, favorecendo o desenvolvimento econômico e social do País. A esse fenômeno chama-se de "bônus demográfico”, “dividendo demográfico" ou "janela de oportunidade”.

Contudo, segundo Kurtenbach (2013, p. 8), de nada adiantará essa janela de oportunidade "se o país não for capaz de absorver a mão de obra disponível e incentivar as potencialidades das pessoas capazes de contribuir para a elevação da produção e da produtividade.”

Conforme o Gráfico 1, verifica-se que a população do Brasil continua em ascensão: 
Gráfico 1 - População: atual e projetada para o Brasil (1950 até 2100)

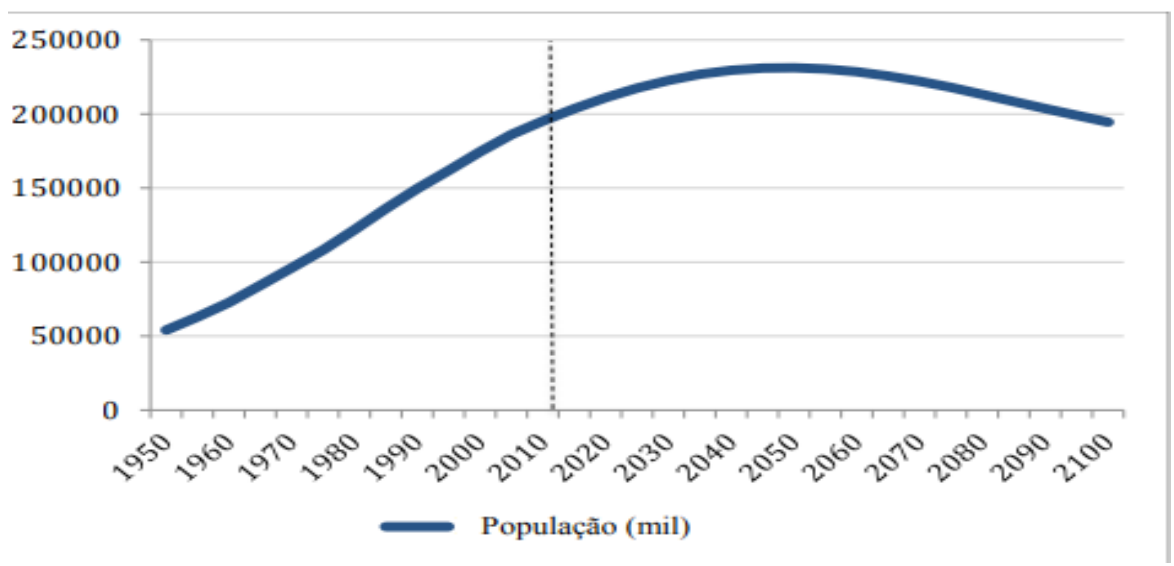

Fonte: Kurtenbach (2013).

Essa ascensão da população aliada ao bônus demográfico configura-se como um importante cenário para o crescimento econômico, que como citado anteriormente, não será automático, dependerá do mix de políticas para tornar seus benefícios maiores.

Conforme Paulani e Braga (2010, p. 257), “é de se esperar que, quanto maior for a população, maior será a magnitude do produto.” Geralmente, o aspecto populacional é usado como divisor de indicadores para determinar a qualidade do cálculo, como, por exemplo, o PIB per capita, a renda per capita e o consumo de água e energia per capita.

O PIB per capita foi o primeiro indicador utilizado para atender à necessidade de medir a qualidade de vida. O cálculo consiste em dividir o valor do PIB total pelo número de habitantes de determinada área em estudo.

O crescimento da riqueza de um território deve acompanhar o crescimento populacional ou vice-versa. Países que têm um PIB elevado, por serem grandes e terem muitos habitantes, não necessariamente terão um PIB per capita elevado, já que a renda é dividida por muitas pessoas. O que se pode destacar também é que “o produto per capita tende a ser potencializado quando a população em idade ativa é relativamente alta e comprimido quando grande parte da população é composta por jovens e idosos dependentes.” (KURTENBACH, 2013, p. 7).

De acordo com Feijó e Ramos (2013), o PIB per capita não seria um bom indicador de bem-estar, tendo em vista que o conceito de PIB leva em consideração o valor agregado resultado de atividade produtiva, não considerando, por exemplo, as horas de lazer do empregado. 
Dessa maneira, no caso de aumentar a jornada de trabalho e reduzir o tempo de folga do trabalhador, o indicador PIB cresce, movimentando a economia, mas a qualidade de vida do empregado frente às horas trabalhadas é cada vez mais desfavorável.

Além disso, o PIB per capita mede a renda média da população, e em países como o Brasil, que a distribuição de renda é desigual, essa medida pode estar distorcida da realidade experienciada pelos habitantes da região.

\subsection{DESENVOLVIMENTO ECONÔMICO SEGUNDO O ÍNDICE FIRJAN DE DESENVOLVIMENTO MUNICIPAL}

O Índice Firjan de Desenvolvimento Municipal (IFDM) foi criado em 2008, baseado no Índice de Desenvolvimento Humano Municipal (IDHM) e inclui no seu cálculo variáveis utilizadas pelo IDHM como educação, saúde, emprego e renda. A diferença dos índices está no sentido de que no IFDM as variáveis são selecionadas de forma a observar a realidade do município, isto é, a seleção das variáveis está voltada para a realização de uma avaliação da realidade municipal mais profunda com periodicidade anual, ao passo que o IDHM é um indicador mais global e é divulgado segundo os censos demográficos do IBGE, isto é, a sua periodicidade não é anual.

O IFDM foi desenvolvido pelo Sistema Firjan, organização privada e sem fins lucrativos, financiado pelas empresas associadas. Segundo o Sistema Firjan (2015), o procedimento do IFDM traz uma visão mais atualizada, representando com maior nitidez a realidade municipal com a agregação de um conjunto de indicadores brasileiros, como número de empregos com carteira assinada, direitos trabalhistas garantidos, educação de qualidade, crianças nas creches pré-escolas, professores com ensino superior, consultas pré-natal oferecidas às gestantes, entre outros.

Em termos metodológicos, o IFDM utiliza dados de estatísticas públicas oficiais. O índice varia de 0 a 1 , sendo que quanto mais próximo de 1 , maior o desenvolvimento da localidade. Conforme Cócaro, Cardoso e Pereira (2016, p. 199), “o IFDM originou-se da necessidade de se monitorar, periodicamente, as potencialidades de desenvolvimento socioeconômico de uma dada região, considerando as diferentes realidades de sua menor divisão federativa, o município.”

Apesar de o Índice de Desenvolvimento Humano Municipal (IDHM), utilizado pela Organização das Nações Unidas, ser configurado como mais bem-sucedido, ele somente é disponibilizado de 10 em 10 anos, como resultado de dados censitários disponíveis. Dessa forma, o IFDM pode ser empregado em comparações, tanto 
relativas quanto absolutas, entre os municípios ao longo do tempo, o que permite detalhar se a melhora ou piora relativa decorre da adoção de políticas específicas ou se o resultado obtido é apenas reflexo da queda dos demais municípios (CÓCARO; CARDOSO; PEREIRA, 2016).

\section{ASPECTOS METODOLÓGICOS}

Este estudo caracteriza-se como descritivo, em relação aos objetivos; bibliográfico e documental, quanto aos procedimentos, e quantitativo, quanto à abordagem do problema. A análise bibliográfica ocorreu durante a realização do estudo, enquanto que a análise documental ocorreu nos meses de agosto e setembro de 2017. Dessa forma, foram coletados os dados referentes aos valores adicionados das atividades econômicas e do PIB das cidades do Rio Grande do Norte, assim como o quantitativo da população divulgado no sítio do IBGE. Adicionalmente, no sítio do Sistema Firjan foram coletados dados do IFDM.

A população compreende todos os municípios do Rio Grande do Norte, isto é, 167 municípios, segundo o censo demográfico de 2010 (IBGE, 2010). No entanto, foram obtidos dados referentes a 166 municípios, uma vez que o Município de Pilões não apresentou todos os dados necessários para a realização do estudo. O período do estudo compreende os anos de 2010 a 2013 e justifica-se pelo fato de que os dados dos anos posteriores não estão disponíveis à consulta no sítio do IBGE, como demandados nesta pesquisa.

Com o intuito de analisar a evolução do valor adicionado das atividades econômicas do Rio Grande do Norte relativamente ao PIB, foi estimado um modelo de dados em painel com as variáveis dos municípios do Estado. Como já discutido anteriormente, a DVA é considerada uma importante aliada na formação do Produto Interno Bruto, além disso, para complementar o estudo, foram adicionadas também ao modelo as variáveis de controle população e IFDM.

Optou-se pelo método estatístico regressão por mínimos quadrados ordinários com dados em painel, pois conforme Gujarati e Porter (2011), o método combina séries temporais com observações de corte transversal, oferecendo dados mais informativos, maior variabilidade, mais graus de liberdade, mais eficiência e menos colinearidade entre as variáveis. Em síntese, os modelos de dados em painel oferecem uma série de vantagens em relação aos modelos de corte transversal ou de séries temporais, em especial, a heterogeneidade dos indivíduos que é levada em consideração. 
Os dados dos municípios do Estado do Rio Grande do Norte foram tabulados em uma planilha eletrônica. Posteriormente, foi utilizado software estatístico para o tratamento quantitativo do modelo proposto.

Espera-se que os valores adicionados estejam relacionados de forma positiva com o PIB, conforme a literatura afirma ao considerar que toda riqueza gerada pela economia de uma nação resulte da soma do valor adicionado das empresas (DE LUCA, 2009). O IFDM foi incluído no modelo como variável que mede o desenvolvimento econômico; o sinal esperado é positivo, pois se entende que quanto maior o desenvolvimento, maior será o PIB, da mesma forma a variável população, espera-se que se relacione de forma positiva com o PIB, pois "é de se esperar que, quanto maior for a população, maior será a magnitude do produto.” (PAULANI; BRAGA, 2010, p. 257).

No Quadro 1 tem-se a especificação das variáveis utilizadas e os respectivos sinais esperados do modelo proposto:

Quadro 1 - Resumo das variáveis utilizadas e seus respectivos sinais esperados

\begin{tabular}{|c|c|}
\hline VARIÁVEL & SINAL ESPERADO \\
\hline Produto Interno Bruto (PIB) & Variável dependente \\
\hline Valor Adicionado da Agropecuária (VAA) & + \\
\hline Valor Adicionado da Indústria (VAI) & + \\
\hline Valor Adicionado dos Serviços (VAS) & + \\
\hline Valor Adicionado da Administração Pública (VAP) & + \\
\hline Índice Firjan de Desenvolvimento Municipal (IFDM) & + \\
\hline População (POP) & + \\
\hline
\end{tabular}

Fonte: os autores.

\section{ANÁLISE DOS RESULTADOS}

\subsection{ANÁLISE DESCRITIVA}

A Tabela 1 apresenta a estatística descritiva dos dados tabulados entre os anos 2010 e 2013, informando a média, o desvio padrão e os valores mínimos e máximos das variáveis investigadas: 
Tabela 1 - Estatística descritiva

\begin{tabular}{|c|c|c|c|c|c|c|}
\hline VARIÁVEIS & ANO & $\mathbf{N}$ & MÉDIA & DES. PADRÃO & MíN. & MAX. \\
\hline \multirow{4}{*}{ PIB } & 2010 & 166 & $217.868,6$ & $1.081 .840,0$ & $9.051,4$ & $12.918 .972,0$ \\
\hline & 2011 & 166 & $246.746,9$ & $1.226 .824,0$ & $10.695,0$ & $14.701 .974,0$ \\
\hline & 2012 & 166 & $279.448,2$ & $1.382 .781,0$ & $-19.046,4$ & $16.542 .636,0$ \\
\hline & 2013 & 166 & $310.200,1$ & $1.540 .651,0$ & 4.198,9 & $18.465 .101,0$ \\
\hline \multirow{4}{*}{ VAA } & 2010 & 166 & $6.912,5$ & $12.598,4$ & 345,6 & $98.080,5$ \\
\hline & 2011 & 166 & $8.020,3$ & $13.409,3$ & 523,7 & 118.769,3 \\
\hline & 2012 & 166 & $7.838,8$ & $15.480,1$ & 296,4 & $129.225,5$ \\
\hline & 2013 & 166 & $8.940,7$ & $17.019,2$ & 302,5 & $141.403,4$ \\
\hline \multirow{4}{*}{ VAI } & 2010 & 166 & $46.279,1$ & $196.136,8$ & 329,7 & $1.851 .697,0$ \\
\hline & 2011 & 166 & $53.962,0$ & $236.687,4$ & $-108.114,4$ & 2.338.121,0 \\
\hline & 2012 & 166 & $61.811,4$ & 273.081,2 & $-417.323,1$ & $2.654 .537,0$ \\
\hline & 2013 & 166 & $64.673,4$ & $295.904,9$ & $-438.113,7$ & 2.979.331,0 \\
\hline \multirow{4}{*}{ VAS } & 2010 & 166 & $85.839,0$ & $570.947,0$ & $1.720,7$ & 7.051.965,0 \\
\hline & 2011 & 166 & $95.477,6$ & 630.948,3 & $2.011,4$ & 7.818.260,0 \\
\hline & 2012 & 166 & $112.156,9$ & $729.432,1$ & $2.288,8$ & $9.033 .245,0$ \\
\hline & 2013 & 166 & $126.075,2$ & 817.899,7 & $2.504,1$ & 10122367,0 \\
\hline \multirow{4}{*}{ VAP } & 2010 & 166 & $54.534,0$ & $191.420,1$ & $6.168,7$ & 2.306.696,0 \\
\hline & 2011 & 166 & $61.670,7$ & $217.558,9$ & $7.261,6$ & 2.620.968,0 \\
\hline & 2012 & 166 & $66.593,2$ & $232.047,5$ & $8.038,2$ & $2.790 .257,0$ \\
\hline & 2013 & 166 & $76.695,1$ & 261.546,9 & $8.429,7$ & $3.126 .281,0$ \\
\hline \multirow{4}{*}{ IFDM } & 2010 & 166 & 0,5766 & 0,0633 & 0,4035 & 0,7639 \\
\hline & 2011 & 166 & 0,5827 & 0,0612 & 0,3967 & 0,7603 \\
\hline & 2012 & 166 & 0,5965 & 0,0578 & 0,4118 & 0,7652 \\
\hline & 2013 & 166 & 0,6099 & 0,0548 & 0,4735 & 0,7706 \\
\hline \multirow{4}{*}{ POP } & 2010 & 166 & $19.064,3$ & $67.152,9$ & $1.618,0$ & $803.811,0$ \\
\hline & 2011 & 166 & $19.248,0$ & $67.840,8$ & $1.626,0$ & $810.780,0$ \\
\hline & 2012 & 166 & $19.425,8$ & $68.511,9$ & $1.633,0$ & $817.590,0$ \\
\hline & 2013 & 166 & $20.302,9$ & $71.705,6$ & $1.696,0$ & $853.928,0$ \\
\hline
\end{tabular}

Fonte: os autores.

No que diz respeito à análise descritiva, por meio da Tabela 1, observa-se que do total de municípios analisados do Estado do Rio Grande do Norte no período em estudo, o maior valor médio do PIB foi de 310.200,1, em 2013, com um elevado 
desvio padrão de 1.540.651, demonstrando, assim, a evolução desse indicador bem como a elevada dispersão dos dados em relação à média.

Do mesmo modo que, ao passar dos anos, o valor médio do PIB cresceu, as demais variáveis também apresentaram crescimento no seu valor médio, com exceção do valor adicionado da agropecuária. A oscilação desse setor deve-se aos problemas climáticos enfrentados no interior do Estado do Rio Grande do Norte. O ano 2011 foi considerado o último bom inverno, obtendo um ótimo crescimento, entretanto, com a situação adversa no ano posterior, houve o decaimento do setor (CHUVAS..., 2016).

Ao analisar individualmente os municípios, a atividade mais representativa, em valores brutos, é a administração pública nos anos em estudo. No entanto, os 166 municípios da amostra, consoante a Tabela 1, demonstraram que, em valores globais, o setor de serviços é o mais relevante para a formação do PIB. Destaque para o comércio, serviços de reparação de veículos automotivos e motocicletas, e alimentação e alojamento. Estes últimos são bastante relacionados ao turismo, atividade importante para o Estado.

Curiosamente, os serviços de informação e comunicação também têm demonstrado notável crescimento, por intermédio das empresas de telecomunicações, operadoras de telefonia, provedores de internet, portais de notícia e meios de comunicação em geral.

Vale destacar que mesmo tendo como resultado negativo a indústria da extração mineral e a retração da indústria de transformação, representada principalmente pela atividade têxtil, considerando que, inclusive em 2012 uma indústria desse ramo acabou fechando, o valor adicionado da indústria configurou-se em crescimento, com destaque para a construção civil, sobretudo em decorrência das obras para a Copa do Mundo de 2014.

Os valores máximos concentram-se entre os municípios mais populosos. O maior IFDM pertence ao Município de Parnamirim, e o maior valor adicionado da agropecuária a Mossoró; os demais valores máximos da estatística descritiva pertencem à Capital Natal.

A Cidade de Viçosa, a menos populosa do Estado, também possui os valores mínimos das variáveis: valor adicionado da agropecuária, dos serviços e da administração pública. O IFDM mínimo refere-se ao Município de Governador Dix-Sept Rosado, com 0,3967. Destaca-se que o Município de Guamaré, conhecido pela produção de petróleo e que possui em seu território polo industrial e uma refinaria da Petrobras, apresentou valor adicionado da indústria negativo. Curiosamente, em 2011, mesmo a Cidade se apresentando com o menor valor da indústria no Estado, obteve a $18^{\mathrm{a}}$ renda 
per capita do Brasil, principalmente por causa dos serviços. Contudo, em 2013, alcançou o pior PIB do Estado.

Em relação ao valor adicionado da administração pública, ressalta-se que em 2011 ocorreu o que ficou conhecimento como "Greve Geral”, todavia não impactou o crescimento dessa atividade, que conforme a Tabela 1, mostra-se como a segunda mais relevante do Estado. Segundo Santos (2015), o chefe da Unidade do IBGE do Rio Grande do Norte, Aldemir Freire, comenta que essa relevância do setor público ocorre em decorrência da remuneração de pessoal, que na região Nordeste tende a ser maior que no Sul e no Sudeste, tornando o setor público um peso elevado. Ele afirma: “Quanto mais desenvolvido é o estado, mais baixo é peso do setor público" (informação verbal), por isso, em termos de desenvolvimento econômico, seria preferível que cada vez mais o valor adicionado da administração pública fosse menor.

Analisando a média do IFDM, observa-se crescimento do indicador de 2010 a 2012. Naquele período, o Estado esteve ocupando a faixa de desenvolvimento regular, passando à faixa de desenvolvimento moderado, no ano 2013. Essa média pode ser explicada pelo desenvolvimento desigual das cidades, por exemplo, apesar de Parnamirim, em 2013, obter um IFDM de 0,7706, Governador Dix-Sept Rosado obteve 0,4735 no mesmo ano. Essa desigualdade entre os municípios também pode ser verificada por meio do PIB, as Cidades de Natal, Mossoró e Parnamirim que possuem os três maiores PIBs são responsáveis por mais da metade do PIB do Estado.

\subsection{ANÁLISE ECONOMÉTRICA}

Antes de realizar a regressão com dados em painel, torna-se importante verificar se os dados devem ser dispostos em painel ou em pooled. Nesse sentido, por meio do teste de Breusch-Pagan, verificou-se que a regressão deve ser estimada em painel, uma vez que o $p$-value encontrado foi 0,0000 .

Nessa perspectiva, realizou-se o teste de Hausman com o objetivo de constatar se os dados devem ser estimados em efeitos fixos ou aleatórios. Com base no p-value de 0,000, observa-se que o modelo deve ser estimado em painel para efeitos fixos, ou seja, as variáveis variam entre os indivíduos e permanecem constantes ao longo do tempo.

Por fim, visando corrigir o problema de heterocedasticidade no modelo de efeitos fixos, uma vez que o teste de Wald apresentou um p-value de 0,000, foram utilizados estimadores robustos. 
Na Tabela 2 especifica-se mais sobre os resultados encontrados do modelo da regressão em dados em painel:

Tabela 2 - Resultados da regressão em dados em painel

\begin{tabular}{|c|c|}
\hline Variáveis & (1) \\
\hline \multirow[b]{2}{*}{ VAA } & $1,3913 * * *$ \\
\hline & $(0,1575)$ \\
\hline \multirow[t]{2}{*}{ VAI } & $1,0221 * * *$ \\
\hline & $(0,0192)$ \\
\hline \multirow[b]{2}{*}{ VAS } & $1,0757 * * *$ \\
\hline & $(0,0295)$ \\
\hline \multirow[b]{2}{*}{ VAP } & $1,3838 * * *$ \\
\hline & $(0,1370)$ \\
\hline \multirow[b]{2}{*}{ IFDM } & $-12,0927^{*}$ \\
\hline & $(7,1152)$ \\
\hline \multirow[b]{2}{*}{ POP } & $-1,1175$ \\
\hline & $(1,4246)$ \\
\hline \multirow{2}{*}{ Constante } & 20941,58 \\
\hline & $(23529,76)$ \\
\hline Observações & 664 \\
\hline Número de cidades & 166 \\
\hline
\end{tabular}

Fonte: os autores.

Nota: Erro padrão entre parênteses; *** Estatisticamente significante a 1\%;

** Estatisticamente significante a 5\%; * Estatisticamente significante a 10\%.

De acordo com os resultados obtidos na Tabela 2, observa-se que os quatro valores adicionados das atividades econômicas do Estado do Rio Grande do Norte (agropecuária, indústria, serviços e administração pública) influenciam positivamente o Produto Interno Bruto, denotando-se estatisticamente significantes, conforme o que preconiza a literatura. Dessa forma, verifica-se que a Demonstração do Valor Adicionado tem o papel fundamental de evidenciar a contribuição de cada empresa na geração da riqueza nacional, isto é, a sua contribuição para a formação do Produto Interno Bruto.

Confronta-se o sinal da variável população ao que a literatura afirma em relação ao entendimento, de que "é de se esperar que, quanto maior for a população, maior será a magnitude do produto.” (PAULANI; BRAGA, 2010, p. 257). A popula- 
ção relacionou-se negativamente com o Produto Interno Bruto, corroborando, assim, a perspectiva malthusiana de que o crescimento da população não contribui para o aumento do valor agregado, e, consequentemente, levantam-se hipóteses acerca da demografia, segundo o processo de inversão da pirâmide etária, e de que a renda está distribuída de forma desigual no Estado do Rio Grande do Norte.

A variável de controle do desenvolvimento econômico IFDM apresenta-se, ao nível de $10 \%$, estatisticamente significante, influenciando negativamente com o Produto Interno Bruto, comprovando o que evidenciam Siqueira (2014) e Philipsen (2015) quando afirmam que o PIB demonstra o crescimento econômico e não o desenvolvimento econômico. Esses conceitos trazem consigo significâncias tão diferenciadas que chegam a ser inversamente proporcionais.

O crescimento econômico diz respeito à riqueza gerada, enquanto que o desenvolvimento econômico é um conceito mais amplo que leva em consideração a qualidade de vida da população e a redução das diferenças econômicas e sociais. Nesse último ponto, do resultado da variável população e das características históricas do Estado, pode-se inferir que no Rio Grande do Norte a renda não é bem distribuída.

A respeito da educação, parâmetro medido pelo IFDM, por exemplo, em 2013 o Índice de Desenvolvimento da Educação Básica (IDEB) do Rio Grande do Norte foi um dos piores do Brasil, ao passo que uma determinada Instituição Educacional Privada do Estado no mesmo ano esteve entre as 30 maiores notas do Exame Nacional do Ensino Médio (ENEM).

Diante disso, nota-se que de fato as atividades econômicas do Estado do Rio Grande do Norte influenciam de forma positiva o PIB, tornando-se estatisticamente significante, ou seja, conforme aumenta o valor da riqueza gerada pelos municípios potiguares, qualquer que seja o valor adicionado, aumenta o PIB. Já as variáveis de controle população e IFDM se comportaram de forma inversa, isto é, quanto maior a população, menor o PIB, hipótese essa que vai ao encontro dos ideais de controle de natalidade e demonstra a má distribuição de renda. O IFDM também se comporta da forma que quanto maior, menor será o PIB, revelando que os índices em questão medem conceitos distintos, e que o alto PIB de uma localidade não significa dizer, necessariamente, que é sinal de qualidade de vida.

\section{CONCLUSÃO}

Segundo o Comitê de Pronunciamentos Contábeis (2008), a DVA está fundamentada em conceitos macroeconômicos e, por isso, eliminando os valores que repre- 
sentam a dupla contagem, busca apresentar a parcela de contribuição que a entidade tem na formação do PIB. Dessa forma, neste estudo teve-se por objetivo principal analisar a relação dos valores adicionados das atividades econômicas do Rio Grande do Norte (agropecuária, indústria, serviços e administração pública) relativamente ao Produto Interno Bruto.

Esta pesquisa diferenciou-se das demais averiguadas na área por investigar variáveis de controle relacionadas ao PIB: a população e o IFDM. A amostra pesquisada compreende 166 municípios do Estado no período de 2010 a 2013, sendo as análises realizadas por meio da regressão com dados em painel, o que permitiu a análise de um elevado número de cidades em um intervalo de tempo.

Mediante os resultados obtidos no estudo, identificou-se a evolução dos indicadores do Estado, principalmente do PIB, que apresentou elevado desvio padrão, demonstrando, assim, a dispersão dos dados em relação à média. Sobre isso, foi possível verificar que as cidades com os maiores PIBs do período em estudo (Natal, Mossoró e Parnamirim) são responsáveis por mais da metade do PIB do Estado.

Averiguou-se que houve relação positiva e estatisticamente significativa do Produto Interno Bruto com as atividades econômicas do Estado, ou seja, o PIB relacionou satisfatoriamente e diretamente proporcionou com as Demonstrações dos Valores Adicionados da agropecuária, indústria, serviços e administração pública, conforme a literatura.

Em relação às variáveis de controle, o IFDM apresentou-se negativamente relacionado com o PIB, confirmando o que foi afirmado por Kuznets $(1934$, p. 7) criador do PIB, que “o bem-estar de uma nação dificilmente pode ser aferido pela medida da renda nacional”, o que pode ser notado pelo cálculo de ambas as variáveis. O IFDM, representando o desenvolvimento econômico, leva em consideração a educação, a saúde, o emprego e a renda, enquanto que o PIB considera no cálculo tudo o que equivale à produção de uma localidade.

A variável população também se relacionou negativamente em relação ao PIB, apesar do cenário verificado de crescimento populacional e de bônus demográfico. Com o resultado obtido, reflete-se sobre como as políticas governamentais estão adequadas para o aproveitamento da primeira fase da transição demográfica de elevação da população economicamente ativa, além da característica histórica brasileira, em que a renda é má distribuída.

Com base nos resultados apresentados, conclui-se que o valor adicionado das atividades econômicas do Estado do Rio Grande do Norte (agropecuária, indústria, serviços e administração pública) possui relação com o PIB, atestando o que afirma 
a literatura e que as variáveis de controle escolhidas se relacionam de forma inversamente proporcional, diferentemente ao que se esperava.

Assim, verifica-se que este estudo contribui também para o contexto das informações regionais apresentadas, destacando a responsabilidade social corporativa, tema considerado importante nas últimas décadas, e conforme descrito por Taiarol, Raimundini e Behr (2011), promove o crescimento empresarial e o desenvolvimento social, tendo em vista as relações entre as organizações e a comunidade em geral.

Como sugestão de estudos futuros, já que o PIB tem características macroeconômicas, sugere-se a escolha de uma amostra maior composta por uma região e/ou pelo Brasil; além disso, conforme os dados são publicados no sítio do IBGE, considera-se importante atualizar os dados da pesquisa.

\section{REFERÊNCIAS}

ALVES, J. E. D.; BRUNO, M. A. P. População e Crescimento Econômico de Longo Prazo no Brasil: como aproveitar a janela de oportunidade demográfica? In: ENCONTRO NACIONAL DE ESTUDOS POPULACIONAIS, 15., 2006, Caxambu. Anais... Campinas: ABEP, 2006.

ALVES, J. E. D.; VASCONCELOS, D. de S.; CARVALHO, A. A. de. Estrutura etária, bônus demográfico e população economicamente ativa no Brasil: cenários de longo prazo e suas implicações para o mercado de trabalho. Brasília, DF: IPEA, 2010.

ARAÚJO, E.; FAJARDO, J.; TAVANI, L. C. di. CAPM usando uma carteira sintética do PIB Brasileiro. Estudos Econômicos, São Paulo, v. 36, n. 3, p. 465-505, 2006.

BARROS, C. M. E. et al. Relevância do Valor Adicionado: Um Estudo Empírico em Sociedades Anônimas Abertas. Registro Contábil, v. 4, n. 3, p. 147-162, 2013.

\section{CHUVAS SUPERAM 2.000 MM EM ANO DE BOM INVERNO. Tribuna do} Norte, 14 maio 2016. Disponível em: <http://www.tribunadonorte.com.br/noticia/ chuvas-superam-2-000-mm-em-ano-de-bom-inverno/346227>. Acesso em: 09 out. 2017.

CÓCARO, H.; CARDOSO, R. F.; PEREIRA, J. R. Territórios da Cidadania do estado de Mato Grosso: uma avaliação socioeconômica utilizando o índice FIRJAN. Interações, Campo Grande, v. 17, n. 2, 2016. 
COMITÊ DE PRONUNCIAMENTOS CONTÁBEIS. Pronunciamento técnico CPC 09: Demonstração Valor Adicionado. 2008. Disponível em: <http://www.cpc. org.br/CPC/Documentos-Emitidos/ Pronunciamentos/Pronunciamento?Id=40>. Acesso em: 13 set. 2017.

COSTA, C. L. de O.; GUIMARÃES, T. R.; MELLO, L. C. B. de B. Os possíveis benefícios gerados pela obrigatoriedade da publicação da demonstração do valor adicionado pelas empresas de capital aberto. Revista de Contabilidade do Mestrado em Ciências Contábeis da UERJ, v. 18, n. 3, p. 77-93, 2013.

CUNHA, J. V. A. da. Demonstração contábil do valor adicionado - DVA: um instrumento de mensuração da distribuição da riqueza das empresas para os funcionários. 2002. Dissertação (Mestrado em Controladoria e Contabilidade)-Universidade de São Paulo, São Paulo, 2002.

CUNHA, J. V. A. da; RIBEIRO, M. de S.; SANTOS, A. dos. A demonstração do valor adicionado como instrumento de mensuração da distribuição da riqueza. Revista Contabilidade \& Finanças, v. 16, n. 37, p. 7-23, 2005.

DALLABONA, L. F.; MASCARELLO, G.; KROETZ, M. Relação entre os indicadores de desempenho e o valor adicionado distribuído aos agentes colaboradores de empresas listadas na BM\&FBovespa. Revista Catarinense da Ciência Contábil, v. 13, n. 39, p. 49-63, 2014.

DEGENHART, L.; VOGT, M.; HEIN, N. Análise da relação do produto interno bruto dos municípios do estado de Santa Catarina com as demonstrações do valor adicionado. Revista Contemporânea de Contabilidade, v. 11, n. 24, 2014.

DE LUCA, M. M. M. Demonstração do Valor Adicionado: do cálculo da Riqueza Criada pela Empresa ao Valor do PIB. 2. ed. São Paulo: Atlas, 2009.

DE SOUSA, F. A. et al. Responsabilidade social empresarial: uma análise sobre a correlação entre a variação do índice de sustentabilidade empresarial (ISE) e o lucro das empresas socialmente responsáveis que compõem esse índice. Revista Reunir, v. 1, n. 1, p. 52-68, 2015.

FEIJÓ, C. A.; RAMOS, R. L. O. Contabilidade Social. 4. ed. Rio de Janeiro: Elsevier, 2013. 
FÉLIX JÚNIOR, L. A. et al. Divulgação de informações sobre recursos humanos e os fatores que influenciam sua evidenciação voluntária nos relatórios da administração. Enfoque: Reflexão Contábil, v. 37, n. 1, p. 129-146, 2018.

FONSECA, M. V.; PAIVA, S. B. Demonstração do valor adicionado: uma análise do valor adicionado do Banco do Brasil no período 2008-2010. Veredas Favip-Revista Eletrônica de Ciências, v. 5, n. 1-2, 2013.

GUJARATI, D. N.; PORTER, D. C. Econométria Básica. 5. ed. Porto Alegre: AMGH, 2011.

HALLER, A.; VAN STADEN, C. The value added statement - an appropriate instrument for Integrated Reporting. Accounting, Auditing \& Accountability Journal, v. 27, i. 7, p. 1190-1216, 2014.

IBGE. 2010. Estatísticas - PIB municípios. Disponível em: < http://downloads. ibge.gov.br/downloads_estatisticas.htm>. Acesso em: 01 ago. 2017.

KROETZ, C. E. S. Balanço social: teoria e prática. São Paulo: Atlas, 2000.

KURTENBACH, M. R. A contribuição de questões demográficas para trajetória de crescimento do Brasil. 2013. 38 p. Monografia (Graduação em Economia)-Pontifícia Universidade Católica do Rio de Janeiro, Rio de Janeiro, 2013.

KUZNETS, S. National income 1929-1932. Senate document, 73rd US Congress, i. 124, 1934.

MACHADO, M. A. V.; MACEDO, M. A. da S.; MACHADO, M. R. Análise da relevância do conteúdo informacional da DVA no mercado de capitais. Revista Contabilidade \& Finanças, v. 26, n. 67, p. 57-59, 2015.

MACHADO, M. R. As informações sociais e ambientais evidenciadas nos relatórios anuais das empresas: a percepção dos usuários. 2010. 168 p. Tese (Doutorado em Ciências Contábeis)-Universidade de São Paulo, São Paulo, 2010.

MARTINS, A. S. R. et al. A percepção contábil nos indicadores sociais e econômicos da Petrobras: petróleo brasileiro S/A com o auxílio do balanço social e demonstração do valor adicionado (DVA). Estudos do ISCA, v. 4, n. 14, p. 1-21, 2016. 
OLIVEIRA, C. E. et al. Um estudo acerca do desempenho social com base no balanço social de empresa do setor de petróleo face à crise financeira internacional. Revista UNEMAT de Contabilidade, v. 5, n. 10, 2016.

PAREDES, B. J. B.; OLIVEIRA, M. R. G. de. O Impacto dos Fatores Macroeconômicos e de Risco Sobre a Mensuração do Valor das Empresas. Revista Universo Contábil, v. 13, n. 2, p. 43, 2017.

PAULANI, L. M.; BRAGA, M. B. A nova contabilidade social. 3. ed. São Paulo: Saraiva, 2010.

PHILIPSEN, D. The little big number: how GDP came to rule the world and what to do about it. Princeton University Press, 2015.

SANTOS, A. Demonstração do valor adicionado: como elaborar e analisar a DVA. 2. ed. São Paulo: Atlas, 2007.

SANTOS, I. PIB da indústria tem queda de 7\% no RN. 2015. Disponível em: $<$ https:// www.novonoticias.com/economia/pib-da-industria-tem-queda-de-7-no-rn>. Acesso em: 08 out. 2017.

SILVA, C. M. et al. Demonstração do Valor Adicionado: Análise da Variação do Coeficiente de Correlação do PIB Brasileiro e do Valor Adicionado da Petrobras em Função das Perdas por Corrupção no Exercício de 2014. SINERGIA - Revista do Instituto de Ciências Econômicas, Administrativas e Contábeis, v. 20, n. 1, p. 57-68, 2016.

SIQUEIRA, E. da S. PIB: um indicador em crise. 2014. Monografia (Graduação em Ciências Econômicas)-Universidade Federal do Paraná, Curitiba, 2014.

SISTEMA FIRJAN. IFDM 2015 - Índice FIRJAN de Desenvolvimento Municipal: Ano Base 2013. 2015. Disponível em: <http://publicacoes.firjan.org.br/ ifdm/2015/files/assets/common/ downloads/publication.pdf>. Acesso em: 09 out. 2017.

TAIAROL, S. M.; RAIMUNDINI, S. L.; BEHR, A. Indicadores Sociais Internos e a Geração de Valor Adicionado: uma análise da relação do Balanço Social e da Demonstração do Valor Adicionado em bancos brasileiros. Revista Reunir, v. 1, n. 2, p. 82-100, 2011. 
VAN STADEN, C. J. The value added statement: bastion of social reporting or dinosaur of financial reporting? New Zealand: Massey University - Palmerston North, 2000.

\section{Como citar este artigo:}

ABNT

FERNANDES, Ruhama Bezerra; TAVARES, Adilson de Lima; AZEVEDO, Yuri Gomes Paiva. Relação entre o valor adicionado das atividades econômicas e o Produto Interno Bruto do Rio Grande do Norte. RACE, Revista de Administração, Contabilidade e Economia, Joaçaba: Ed. Unoesc, v. 17, n. 2, p. 757-782, maio/ago. 2018. Disponível em: <http://editora.unoesc.edu.br/index.php/race>. Acesso em: dia/ mês/ano.

APA

Fernandes, R. B., Tavares, A. de L., \& Azevedo, Y. G. P. (2018). Relação entre o valor adicionado das atividades econômicas e o Produto Interno Bruto do Rio Grande do Norte. RACE, Revista de Administração, Contabilidade e Economia, 17(2), 757-782. Recuperado em dia/mês/ano, de http://editora.unoesc.edu.br/index.php/race 
